\title{
CARACTERIZAÇÃO MORFOLÓGICA E PRODUTIVA E SUAS CORRELAÇÕES EM CULTIVARES DE CANA- DE-AÇÚCAR
}

\author{
Sebastião de Oliveira Maia Júnior ${ }^{1 *}$; João Antônio Carvalho Silva²; Karolyne Priscila Oliveira dos Santos²; Jailma \\ Ribeiro de Andrade"; José Vieira Silva; Laurício Endres".
${ }^{1}$ Doutorando(a) em Agronomia (PPGA), Centro de Ciências Agrárias (CECA), Universidade Federal de Alagoas (UFAL), BR 104 Norte, Km 85, Rio Largo, AL. CEP 57.000-100.
${ }^{2}$ Graduando(a) em Agronomia (PPGA), Centro de Ciências Agrárias (CECA), Universidade Federal de Alagoas (UFAL), BR 104 Norte, Km 85, Rio Largo, AL. CEP 57.000-100.
${ }^{3}$ Professor Dr., Universidade Federal de Alagoas - Av. Manoel Severino Barbosa, Bom Sucesso, Arapiraca, AL CEP:57309-005.
${ }^{4}$ Professor Dr., Centro de Ciências Agrárias (CECA), Universidade Federal de Alagoas (UFAL), BR 104 Norte, Km 85, Rio Largo, AL. CEP 57.000-100.

*Autor para correspondência: Sebastião de Oliveira Maia Júnior, juniormaiagrari@hotmail.com

\begin{abstract}
RESUMO: A cana-de-açúcar é uma das culturas agrícolas mais importantes do mundo, sendo a principal matériaprima para produção de açúcar e bioenergia. 0 presente estudo teve como objetivo avaliar características morfológicas e produtivas e suas correlações em diferentes cultivares de cana-de-açúcar. Foram avaliadas seis cultivares: RB72910, RB99382, RB72454, RB855536, RB92579 e RB931011. As avaliações foram feitas mensalmente dos 60 aos 240 dias após o plantio (DAP). Foram avaliadas características morfológicas e produtivas, e posteriormente correlacionadas dentro de cada época e de cada cultivar. As cultivares RB931011 e RB92579 foram mais altas até os 210 DAP, e ainda tiveram maior peso de colmos e maior largura das folhas, respectivamente. A RB72454 teve o maior diâmetro do colmo e menor perfilhamento. Em todas as cultivares houve correlação da altura da planta com o diâmetro do colmo, a área foliar, o comprimento e a largura da folha. O perfilhamento tem correlação negativa com o diâmetro do colmo e o teor de sólidos solúveis, enquanto que, 0 diâmetro do colmo tem correlação positiva com o teor de sólidos solúveis e o peso de colmos. A área e a largura foliar são bons parâmetros na seleção de cultivares promissoras de cana-de-açúcar, por terem fortes correlações com a produção de colmos.
\end{abstract}

PALAVRAS-CHAVE: Saccharum spp., potencial genético, melhoramento.

\section{MORPHOLOGICAL AND PRODUCTIVE CHARACTERIZATION AND ITS CORRELATIONS IN CULTIVARS OF SUGARCANE}

\begin{abstract}
The sugarcane is one of the more important agricultural crops of the world, being the main raw material for sugar and bioenergy production. The present study had as objective to evaluate morphological and productive characteristics and their correlations in different cultivars of sugarcane. Six cultivars were evaluated: RB72910, RB99382, RB72454, RB855536, RB92579 e RB931011. Evaluations were made monthly from 60 to 240 days after planting (DAP). Morphological and productive characteristics were evaluated and later correlated within each season and each cultivar. The cultivars RB931011 and RB92579 were higher until the 210 DAP, and still had higher stem weight and leaf width, respectively. The RB72454 had the largest stem diameter and lower tillering. In all the cultivars there was correlation of the height of the plant with the diameter of the stem, the leaf area, the length and the width of the leaf. The tillering has a negative correlation with stem diameter and soluble solids content, while stem diameter has positive correlation with soluble solids content and stem weight. The leaf area and width are excellent parameters in the selection of promising cultivars of sugarcane, for having high correlations with the production of stems.
\end{abstract}

KEYWORDS: Saccharum spp., genetic potential, breeding. 


\section{INTRODUÇÃO}

A cana-de-açúcar (Saccharum spp.) é uma cultura de grande importância econômica devido a sua utilização como matéria-prima na indústria de alimentos e produção de biocombustível renovável, sendo o Brasil o maior produtor mundial com área cultivada em torno de 8,838 milhões de hectares (Silva et al., 2007; Conab, 2017).

No cenário nacional, a expansão da cultura vem sendo restringida pela seca (Silva et al., 2007; Medeiros et al., 2013; Vieira et al., 2014). De um lado, encontra-se a maior região produtora, o centro-sul, onde a área de expansão da cultura é o Cerrado, com chuvas concentradas ou até mesmo irregulares o que tem afetado negativamente a cultura (Carlin e Santos, 2009; Silva et al., 2012). De outro lado, regiões tradicionalmente canavieiras como as regiões dos Tabuleiros Costeiros e Zona da Mata do Nordeste, que não dispõem mais de área para expansão, além de apresentarem frequentes estiagens (Oliveira et al., 2007; Costa et al., 2011).

Nesse sentido, torna-se importante identificar cultivares promissoras através da expressão do potencial genético que pode ser avaliado por meio de caracteres morfológicos e produtivos, além do conhecimento das correlações desses caracteres, sendo de fundamental importância para os melhoristas na identificação e organização dos recursos genéticos disponíveis (Souza et al., 2011; Santos et al., 2014) uma vez que a utilização de cultivares adequadas possibilita aumentos de produtividade (Capone et al., 2011).

As características morfológicas podem variar amplamente entre cultivares da mesma espécie (Casler et al., 2004), tornando importante a compreensão dos componentes de crescimento e produtividade para seleção de cultivares existentes (Nyadanu e Dikera, 2014). A maioria dos trabalhos reporta a caracterização morfológica de cultivares de cana-de-açúcar quando impostas a algum tipo de estresse, como seca (Machado et al., 2009; Pincelli e Silva, 2012), temperatura (Sales et al., 2012) e acidez do solo (Santos e Carlin, 2009) não indicando as reais potencialidades entre diferentes cultivares quando cultivadas em condições adequadas.

As plantas sob condições adequadas ao seu desenvolvimento, como umidade e temperatura ideais, conseguem expressar todo seu potencial genético, podendo diferir entre cultivares (Almeida et al., 2010; Silva et al., 2012; Santos et al., 2014). Portanto, critérios morfológicos e produtivos podem facilitar bastante aos melhoristas, na seleção e escolha de cultivares promissoras.

A análise de crescimento de cana-de-açúcar por meio de parâmetros morfológicos, como altura de plantas, diâmetro de colmo, perfilhamento, área foliar, produção de colmos, massa seca e de sacarose, permite identificar eventuais potencialidades produtivas entre diferentes cultivares (Shigaki et al., 2004; Oliveira et al., 2007; Costa et al., 2011; Capone et al., 2011; Pincelli e Silva, 2012; Silva et al., 2012; Santos et al., 2014), evidenciando, portanto, a importância do estudo dessas características como parâmetro indicativo do potencial de produção.

Diante do exposto, objetivou-se com este trabalho avaliar características morfológicas e produtivas de diferentes cultivares de cana-deaçúcar e as correlações entre os caracteres, visando selecionar as que melhor expressem seu potencial produtivo quando cultivadas sob condições adequadas.

\section{MATERIAL E MÉTODOS}

0 experimento foi conduzido sob as coordenadas $9^{\circ} 29^{\prime} 45^{\prime \prime}$ S, $35^{\circ} 49^{\prime} 31^{\prime \prime}$ W, a $127 \mathrm{~m}$ de altitude. $O$ delineamento experimental foi em blocos casualizados com seis tratamentos em três blocos e, quatro repetições por bloco, totalizando 72 unidades experimentais. Os tratamentos corresponderam a seis cultivares de cana-de-açúcar: RB72910, RB92579, RB931011, RB72454, RB855536 e RB99382. Cada unidade experimental foi composta por um vaso de 0,485 $\mathrm{m}$ de diâmetro médio e $0,99 \mathrm{~m}$ de altura preenchido com aproximadamente $180 \mathrm{~kg}$ de solo destorroado, em arranjo espacial de 1,0 por 1,0 m. O solo utilizado foi um Latossolo Amarelo coeso, cujas características físico-químicas encontram-se na Tabela 1. 
Tabela1. Propriedades químicas e físicas do solo utilizado no experimento.

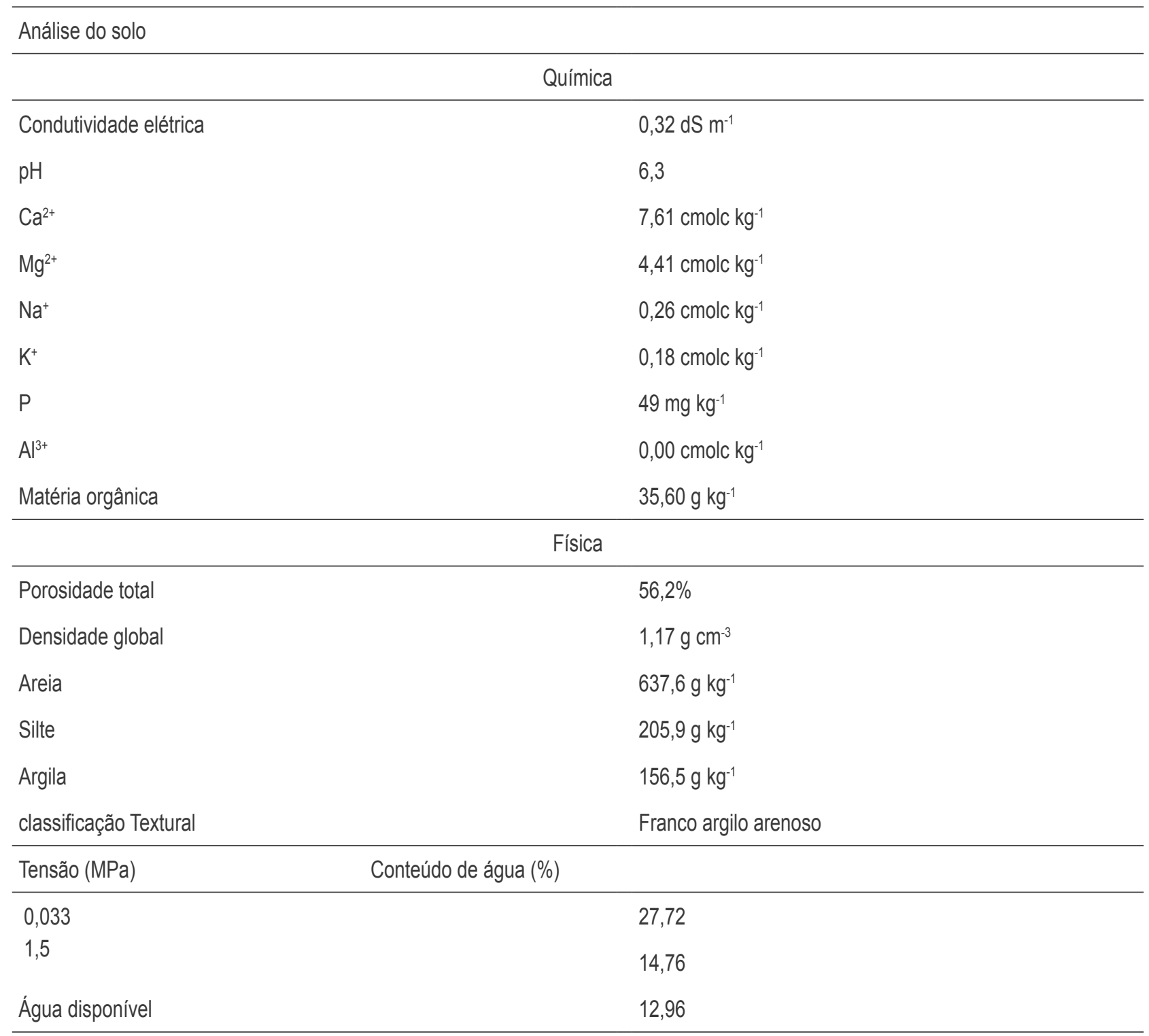

A adubação foi realizada de acordo com as características químicas do solo, conforme recomendações de Vitti et al. (2013).

Ao longo do experimento, a umidade do solo foi mantida próximo à capacidade de campo, e a reposição da água feita por sistema de irrigação pressurizada, com um emissor do tipo micro aspersor instalado em cada vaso.

As condições ambientais representadas pela temperatura média do ar, umidade relativa média e precipitação pluviométrica (Figura 1A, B, C) foram registradas por uma estação meteorológica automatizada, localizada a aproximadamente $200 \mathrm{~m}$ da área experimental. 
Figura 1. Temperatura média do ar $(A)$, umidade relativa média $(B)$ e pluviosidade $(C)$ durante os meses de execução do experimento, Rio Largo - AL, 2014.

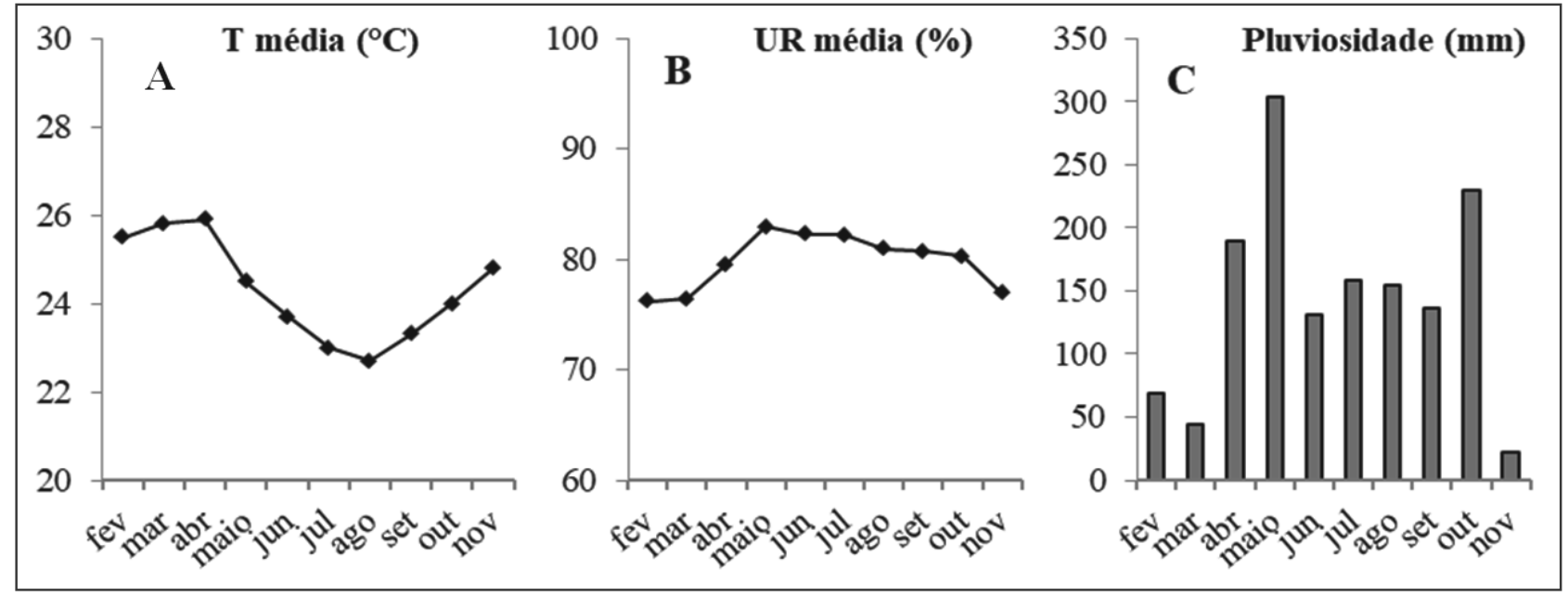

Antes da montagem do experimento, os rebolos contendo uma gema foram plantados previamente em bandejas plásticas para garantir a uniformização das plântulas a serem utilizadas. Trinta dias após o plantio (DAP), três plântulas uniformes foram transferidas para cada vaso.

As características morfológicas foram avaliadas mensalmente dos 60 aos 240 DAP. A altura da planta foi mensurada do nível do solo até a inserção da folha +1 (última folha com lígula aparente), baseando-se no sistema Kuijper (Van Dillewijn, 1952). O diâmetro do colmo foi avaliado com auxílio de um paquímetro digital. 0 número de folhas foi obtido pela contagem, das folhas totalmente expandidas, considerando-se aquelas com pelo menos $20 \%$ de área verde. 0 comprimento e a largura da folha foram mensurados na folha +3 e, a área foliar determinada segundo metodologia descrita por Hermann e Câmara (1999):

Em que: $C$ é o comprimento da folha +3 ; $L$ é a largura da folha $+3 ; 0,75$ é o fator de correção para área foliar da cultura e, $\mathrm{N}$ é o número de folhas com pelo menos $20 \%$ de área verde.

Aos 240 DAP, o experimento foi colhido e as plantas separadas em colmos e folhas. 0 teor de sólidos solúveis (SS) foi avaliado na região basal (terceiro entrenó a partir da base) de um colmo por parcela com auxílio de um furador e, a leitura aferida com uso de um refratômetro digital; para tanto, o furador e o refratômetro foram lavados com água destilada no intervalo de cada amostragem. 0 peso de colmos (PC) foi determinado fresco, tomando-se a média de três plantas por parcela. A fitomassa de folhas foi obtida coletando-se as folhas de uma touceira por parcela e dividindo-se pelo número de perfilhos da respectiva touceira. As folhas foram colocadas em estufa de circulação forçada de ar a $70{ }^{\circ} \mathrm{C}$ até atingirem peso constante.

Os dados foram submetidos à análise de variância pelo Teste $F$, e as médias comparadas pelo teste de Tukey $(p<0,05)$. As variáveis também foram submetidas à análise de correlação, utilizando-se a correlação linear de Pearson.

\section{RESULTADOS}

O crescimento em altura foi linear para todas as cultivares ao longo do período de estudo, com alturas diferentes entre as cultivares até os 210 DAP (Figura 2A). As cultivares RB931011 e RB92579 tiveram maior altura entre os 150 e 210 $\mathrm{DAP}$, sobressaindo-se às demais, enquanto a cultivar RB99382 teve menor altura até os 210 DAP; aos 240 DAP todas as cultivares tiveram altura média de $252,7 \mathrm{~cm}$. 
Figura 2. Altura de plantas $(A)$, diâmetro de colmos $(B)$, número de perfilhos $(C)$, número de folhas $(D)$, comprimento de folhas $(E)$, largura de folhas $(F)$ e área foliar $(G)$ em cultivares de cana-de-açúcar entre os 60 e 240 DAP. **= significativo $(p<0,01),{ }^{*}=$ significativo $(p<0,05)$ e, ns= não significativo pelo teste $F$.
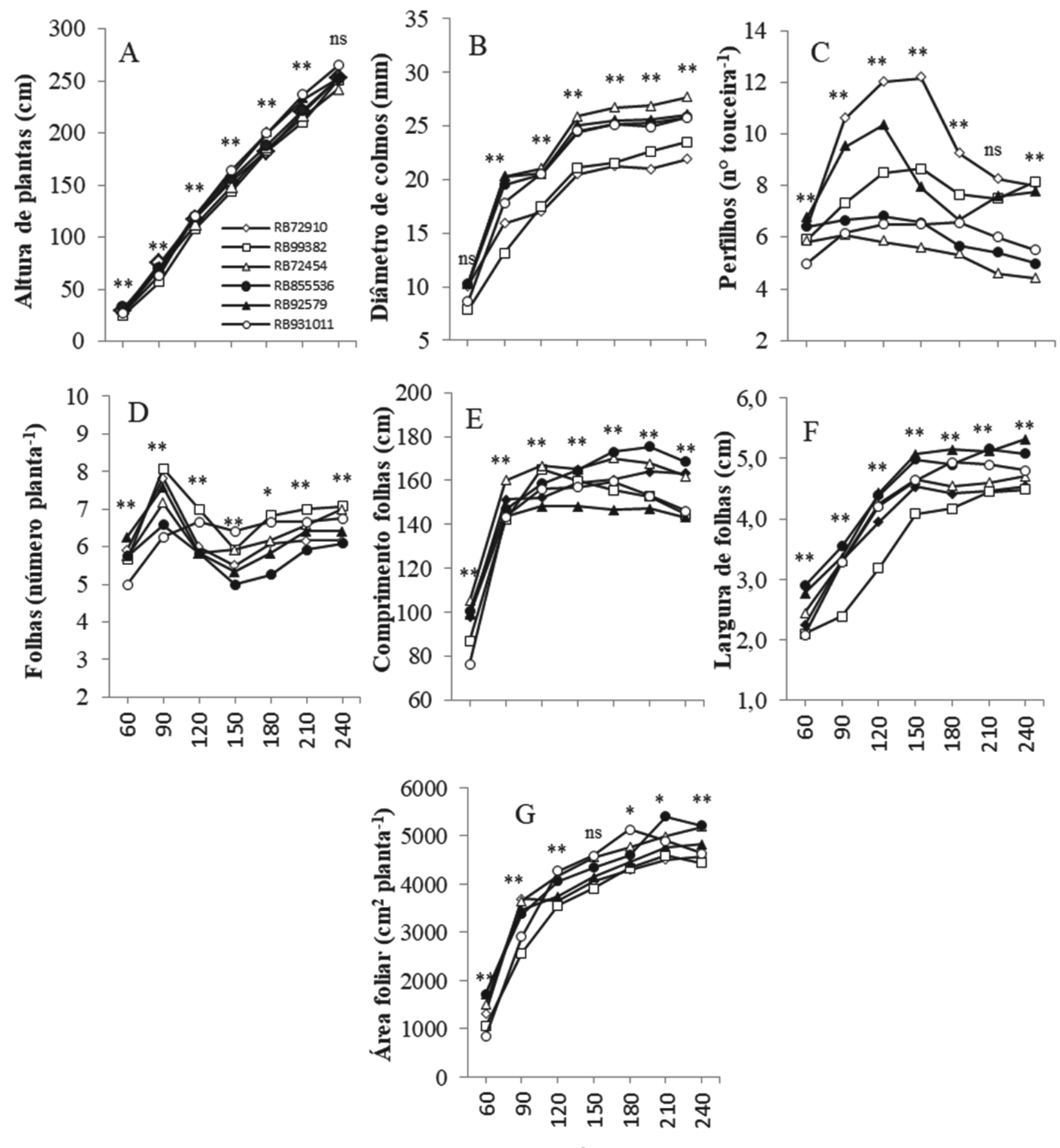

DIAS APÓS PLANTIO

A altura de planta se correlacionou com a área foliar dos 60 aos 240 DAP, com o diâmetro do colmo aos $60,90,150$ e 180 DAP, com a largura da folha dos 60 aos 210 DAP e, com o número de folhas e o peso do colmo aos 240 DAP (Tabela 2). Além disso, em todas as cultivares a altura de plantas se correlacionou com o diâmetro do colmo, a área foliar, o comprimento e a largura da folha (Tabela 3). 
Tabela 2. Correlações entre as características morfológicas: altura de planta (AP), diâmetro do colmo (DC), número de folhas (NF), número de perfilhos (NP), área foliar (AF), comprimento da folha (CF) e largura da folha (LF) dos 60 aos 210 DAP, e características de produção: massa seca de folhas (MSF), teor sólidos solúveis (SS) e peso de colmos (PC) aos 240 DAP em cultivares de cana-de-açúcar $(n=72)$. * significativo até $p<0,05$ pelo teste $t$.

\begin{tabular}{|c|c|c|c|c|c|c|c|c|c|}
\hline \multicolumn{10}{|c|}{$60 \mathrm{DAP}$} \\
\hline & AP & DC & $\mathrm{NP}$ & $\mathrm{NF}$ & CF & LF & AF & MSF & SS \\
\hline$D C$ & $0,484^{*}$ & & & & & & & & \\
\hline NP & 0,145 & $0,274^{*}$ & & & & & & & \\
\hline $\mathrm{NF}$ & $-0,163$ & 0,173 & $0,468^{*}$ & & & & & & \\
\hline $\mathrm{CF}$ & $0,607^{*}$ & $0,509^{*}$ & $0,351^{*}$ & $0,235^{*}$ & & & & & \\
\hline LF & $0,376^{*}$ & $0,451^{*}$ & $0,320^{*}$ & $0,274^{*}$ & $0,610^{*}$ & & & & \\
\hline AF & $0,376^{*}$ & $0,467^{*}$ & $0,461^{*}$ & $0,588^{*}$ & $0,776^{*}$ & $0,888^{*}$ & & & \\
\hline \multicolumn{10}{|c|}{90 DAP } \\
\hline$D C$ & $0,572^{*}$ & & & & & & & & \\
\hline NP & 0,217 & 0,039 & & & & & & & \\
\hline NF & 0,125 & $-0,263^{*}$ & 0,214 & & & & & & \\
\hline $\mathrm{CF}$ & 0,204 & $0,272^{*}$ & $-0,080$ & $-0,102$ & & & & & \\
\hline LF & $0,516^{*}$ & $0,537^{*}$ & 0,148 & $-0,318^{*}$ & $0,255^{*}$ & & & & \\
\hline $\mathrm{AF}$ & $0,546^{*}$ & $0,341^{*}$ & 0,207 & $0,361^{*}$ & $0,574^{*}$ & $0,657^{*}$ & & & \\
\hline \multicolumn{10}{|c|}{120 DAP } \\
\hline $\mathrm{DC}$ & 0,141 & & & & & & & & \\
\hline NP & 0,055 & $-0,392^{*}$ & & & & & & & \\
\hline $\mathrm{NF}$ & 0,010 & $-0,100$ & $-0,098$ & & & & & & \\
\hline CF & $-0,256^{*}$ & 0,046 & $-0,299^{*}$ & 0,085 & & & & & \\
\hline $\mathrm{LF}$ & $0,493^{*}$ & $0,379^{*}$ & $-0,123$ & $-0,281^{*}$ & $-0,176$ & & & & \\
\hline $\mathrm{AF}$ & $0,282^{*}$ & $0,284^{*}$ & $-0,320^{*}$ & $0,413^{*}$ & $0,460^{\circ}$ & $0,574^{*}$ & & & \\
\hline \multicolumn{10}{|c|}{150 DAP } \\
\hline $\mathrm{DC}$ & $0,340^{*}$ & & & & & & & & \\
\hline NP & $-0,148$ & & & & & & & & \\
\hline NF & 0,188 & 0,004 & 0,061 & & & & & & \\
\hline $\mathrm{CF}$ & $-0,225$ & $-0,020$ & $-0,000$ & 0,060 & & & & & \\
\hline $\mathrm{LF}$ & $0,443^{*}$ & $0,569^{*}$ & $-0,166$ & $-0,066$ & $-0,071$ & & & & \\
\hline $\mathrm{AF}$ & $0,311^{*}$ & $0,331^{*}$ & $-0,063$ & $0,698^{*}$ & $0,385^{*}$ & $0,547^{*}$ & & & \\
\hline \multicolumn{10}{|c|}{180 DAP } \\
\hline $\mathrm{DC}$ & $0,319^{*}$ & & & & & & & & \\
\hline NP & $-0,171$ & $-0,532^{*}$ & & & & & & & \\
\hline $\mathrm{NF}$ & 0,206 & $-0,174$ & 0,128 & & & & & & \\
\hline $\mathrm{CF}$ & $-0,141$ & 0,187 & $-0,121$ & $-0,155$ & & & & & \\
\hline LF & $0,529^{*}$ & $0,429^{*}$ & $-0,172$ & $-0,034$ & $-0,045$ & & & & \\
\hline AF & $0,420^{*}$ & $0,289^{*}$ & $-0,099$ & $0,536^{*}$ & $0,387^{*}$ & $0,646^{*}$ & & & \\
\hline \multicolumn{10}{|c|}{$210 \mathrm{DAP}$} \\
\hline DC & 0,157 & & & & & & & & \\
\hline NP & $-0,004$ & $-0,507^{*}$ & & & & & & & \\
\hline $\mathrm{NF}$ & 0,094 & 0,035 & 0,070 & & & & & & \\
\hline $\mathrm{CF}$ & 0,069 & 0,055 & $-0,384^{*}$ & $-0,148$ & & & & & \\
\hline $\mathrm{LF}$ & $0,292^{*}$ & $0,396^{*}$ & $-0,124$ & 0,002 & 0,158 & & & & \\
\hline $\mathrm{AF}$ & $0,277^{*}$ & $0,297^{*}$ & $-0,250^{*}$ & $0,460^{*}$ & $0,568^{*}$ & $0,702^{*}$ & & & \\
\hline \multicolumn{10}{|c|}{240 DAP } \\
\hline DC & $-0,017$ & & & & & & & & \\
\hline NP & 0,136 & $-0,557^{*}$ & & & & & & & \\
\hline $\mathrm{NF}$ & $0,276^{*}$ & 0,191 & 0,091 & & & & & & \\
\hline CF & 0,120 & $-0,003$ & $-0,264^{*}$ & 0,197 & & & & & \\
\hline LF & 0,039 & $0,424^{*}$ & $-0,135$ & $-0,059$ & $-0,037$ & & & & \\
\hline AF & $0,254^{*}$ & $0,334^{*}$ & $-0,169$ & $0,687^{*}$ & $0,653^{*}$ & $0,435^{*}$ & & & \\
\hline MSF & 0,007 & $0,301^{*}$ & $-0,527^{*}$ & $-0,056$ & 0,121 & $-0,129$ & $-0,037$ & & \\
\hline SS & $-0,183$ & $0,450^{*}$ & $-0,329^{*}$ & 0,005 & $-0,152$ & 0,180 & 0,003 & 0,138 & \\
\hline PC & $0,348^{*}$ & $0,306^{*}$ & $-0,185$ & $0,430^{*}$ & 0,122 & $0,245^{*}$ & $0,451^{*}$ & $0,399^{*}$ & 0,028 \\
\hline
\end{tabular}


Tabela 3. Correlações entre características morfológicas: altura de plantas (AP), diâmetro do colmo (DC), número de folhas (NF), número de perfilhos (NP), área foliar (AF), comprimento da folha (CF) e largura da folha (LF) dos 60 aos 240 DAP em cultivares de cana-de-açúcar $(n=84) .{ }^{*}=$ significativo até $p<0,05$ pelo teste t.

\begin{tabular}{|c|c|c|c|c|c|c|}
\hline & AP & $\mathrm{DC}$ & $\mathrm{NP}$ & NF & $\mathrm{CF}$ & LF \\
\hline \multicolumn{7}{|c|}{ RB72910 } \\
\hline$D C$ & $0,747^{*}$ & & & & & \\
\hline$N P$ & $-0,020$ & $0,237^{*}$ & & & & \\
\hline $\mathrm{NF}$ & $-0,134$ & $-0,074$ & 0,058 & & & \\
\hline $\mathrm{CF}$ & $0,717^{\circ}$ & $0,688^{*}$ & $0,318^{*}$ & 0,074 & & \\
\hline LF & $0,842^{*}$ & $0,783^{*}$ & $0,331^{*}$ & $-0,124$ & $0,842^{*}$ & \\
\hline $\mathrm{AF}$ & $0,753^{*}$ & $0,691^{*}$ & $0,311^{*}$ & $0,304^{*}$ & $0,899^{*}$ & $0,883^{*}$ \\
\hline \multicolumn{7}{|c|}{ RB99382 } \\
\hline DC & $0,795^{*}$ & & & & & \\
\hline $\mathrm{NP}$ & $0,346^{*}$ & $0,337^{*}$ & & & & \\
\hline $\mathrm{NF}$ & 0,144 & 0,010 & $0,230^{*}$ & & & \\
\hline $\mathrm{CF}$ & $0,535^{*}$ & $0,629^{*}$ & $0,624^{*}$ & $0,287^{*}$ & & \\
\hline LF & $0,927^{*}$ & $0,819^{*}$ & $0,405^{*}$ & 0,059 & $0,601^{*}$ & \\
\hline $\mathrm{AF}$ & $0,852^{*}$ & $0,753^{*}$ & $0,535^{*}$ & $0,395^{*}$ & $0,778^{*}$ & $0,909^{*}$ \\
\hline \multicolumn{7}{|c|}{ RB72454 } \\
\hline$D C$ & $0,875^{\star}$ & & & & & \\
\hline NP & $-0,535^{*}$ & $-0,389^{*}$ & & & & \\
\hline $\mathrm{NF}$ & 0,199 & $0,262^{*}$ & $-0,218^{*}$ & & & \\
\hline $\mathrm{CF}$ & $0,577^{*}$ & $0,759^{*}$ & $-0,084$ & 0,203 & & \\
\hline LF & $0,805^{*}$ & $0,883^{*}$ & $-0,387^{*}$ & 0,106 & $0,723^{*}$ & \\
\hline $\mathrm{AF}$ & $0,756^{*}$ & $0,857^{\circ}$ & $-0,354^{*}$ & $0,466^{*}$ & $0,841^{*}$ & $0,884^{*}$ \\
\hline \multicolumn{7}{|c|}{ RB855536 } \\
\hline$D C$ & $0,877^{*}$ & & & & & \\
\hline $\mathrm{NP}$ & $-0,498^{*}$ & $-0,332^{*}$ & & & & \\
\hline $\mathrm{NF}$ & $-0,052$ & $-0,058$ & 0,155 & & & \\
\hline $\mathrm{CF}$ & $0,741^{*}$ & $0,859^{\circ}$ & $-0,189$ & $-0,093$ & & \\
\hline LF & $0,863^{*}$ & $0,858^{*}$ & $-0,303^{*}$ & $-0,037$ & $0,744^{*}$ & \\
\hline $\mathrm{AF}$ & $0,831^{*}$ & $0,838^{*}$ & $-0,247^{*}$ & $0,272^{*}$ & $0,829^{*}$ & $0,898^{*}$ \\
\hline \multicolumn{7}{|c|}{ RB92579 } \\
\hline $\mathrm{DC}$ & $0,850^{*}$ & & & & & \\
\hline NP & $-0,137$ & 0,034 & & & & \\
\hline $\mathrm{NF}$ & $-0,112$ & $-0,121$ & 0,133 & & & \\
\hline $\mathrm{CF}$ & $0,559^{*}$ & $0,758^{\circ}$ & 0,138 & 0,012 & & \\
\hline LF & $0,843^{*}$ & $0,858^{*}$ & $-0,085$ & $-0,299^{*}$ & $0,584^{*}$ & \\
\hline $\mathrm{AF}$ & $0,811^{*}$ & $0,845^{*}$ & $-0,002$ & 0,153 & $0,803^{*}$ & $0,841^{*}$ \\
\hline \multicolumn{7}{|c|}{ RB931011 } \\
\hline$D C$ & $0,872^{*}$ & & & & & \\
\hline $\mathrm{NP}$ & 0,099 & $0,237^{*}$ & & & & \\
\hline $\mathrm{NF}$ & $0,495^{*}$ & $0,528^{*}$ & $0,254^{*}$ & & & \\
\hline $\mathrm{CF}$ & $0,623^{*}$ & $0,846^{*}$ & $0,396^{*}$ & $0,582^{*}$ & & \\
\hline LF & $0,861^{*}$ & $0,924^{*}$ & $0,266^{*}$ & $0,532^{*}$ & $0,820^{\circ}$ & \\
\hline AF & $0,804^{*}$ & $0,891^{*}$ & $0,311^{*}$ & $0,723^{*}$ & $0,880^{\circ}$ & $0,948^{*}$ \\
\hline
\end{tabular}


Todas as cultivares apresentaram um aumento do diâmetro do colmo até os 150 DAP, estabilizandose até o final do período de avaliação (Figura 2B). Em média, a partir dos 150 DAP a cultivar RB72454 teve 0 maior diâmetro do colmo, com máximo de $27,7 \mathrm{~mm}$ aos 240 DAP, superior aproximadamente $21 \%$ em relação a cultivar RB72910 que teve o menor diâmetro.

O diâmetro do colmo se correlacionou positivamente com a área foliar e a largura da folha em todos os períodos avaliados (Tabela 2) e para todas as cultivares (Tabela 3), além do teor de sólidos solúveis e peso de colmos aos 240 DAP; 0 diâmetro do colmo também se correlacionou negativamente com o número de perfilhos a partir dos 120 DAP (Tabela 2).

0 número de perfilhos foi bastante variável entre as cultivares (Figura 2C), sendo que RB72910 e RB72454 tiveram o maior e menor perfilhamento, respectivamente, em média de 12 e 5 perfilhos por touceira.

O número de folhas foi máximo aos 90 DAP em todas as cultivares e mínimo aos $150 \mathrm{DAP}$, com variações no decorrer do período e entre as cultivares (Figura 2D). A RB99382 destacou-se com maior número de folhas dos 90 aos 240 DAP, enquanto a RB855536 teve menor número de folhas também no mesmo período (Figura $2 \mathrm{C})$. $\mathrm{O}$ número de folhas se correlacionou positivamente com a área foliar durante todo o período de avaliação (Tabela 2) em que, entre as cultivares, correlação forte foi observada na cultivar RB931011 $\left(0,72^{*}\right)$, mas não na cultivar RB92579 (0,15ns) (Tabela 3).
0 comprimento da folha aumentou consideravelmente entre os 60 e 90 DAP, estabilizandose seguidamente (Figura 2E), enquanto a largura da folha aumentou até os $150 \mathrm{DAP}$, de forma mais gradual (Figura 2F).A partir dos 120 DAP as cultivares RB855536 e RB92579 tiveram maior e menor comprimento da folha, respectivamente (Figuras 2E); contudo, a cultivar RB92579 teve maior largura da folha, ao mesmo tempo que a cultivar RB99382 teve menor largura durante todo o período (Figura $2 \mathrm{~F}$ ).

O comprimento da folha teve forte correlação com o diâmetro do colmo no início do ciclo da cultura (Tabela 2), entretanto, perde essa correlação a partir dos 120 DAP até o final do ciclo, não tendo correlação com o peso final de colmo. Por outro lado, a largura da folha apresentou correlação positiva com o diâmetro do colmo durante todo o ciclo de cultivo e em todas as cultivares, além de correlacionar-se com o peso de colmos (Tabela 2).

A área foliar aumentou acentuadamente dos 60 aos 90 DAP, estabilizando gradualmente até aos 240 DAP (Figura 2G). A cultivar RB855536 teve maior área foliar a partir dos 150 DAP, enquanto a RB99382 teve menor área durante todo o período. $A$ área foliar correlacionou-se positivamente com o comprimento e a largura da folha, e com o diâmetro do colmo em todas as épocas avaliadas (Tabelas 2), e em todas as cultivares (Tabela 3), além de se correlacionar com 0 peso de colmos aos 240 DAP (Tabela 2).

Figura 3. Fitomassa de folhas (A), peso de colmos (B) e teor de sólidos solúveis - SS (C) em cultivares de canade-açúcar aos 240 DAP. Letras diferentes entre barras indicam diferença significativa pelo teste de Tukey $(p<0,05)$.

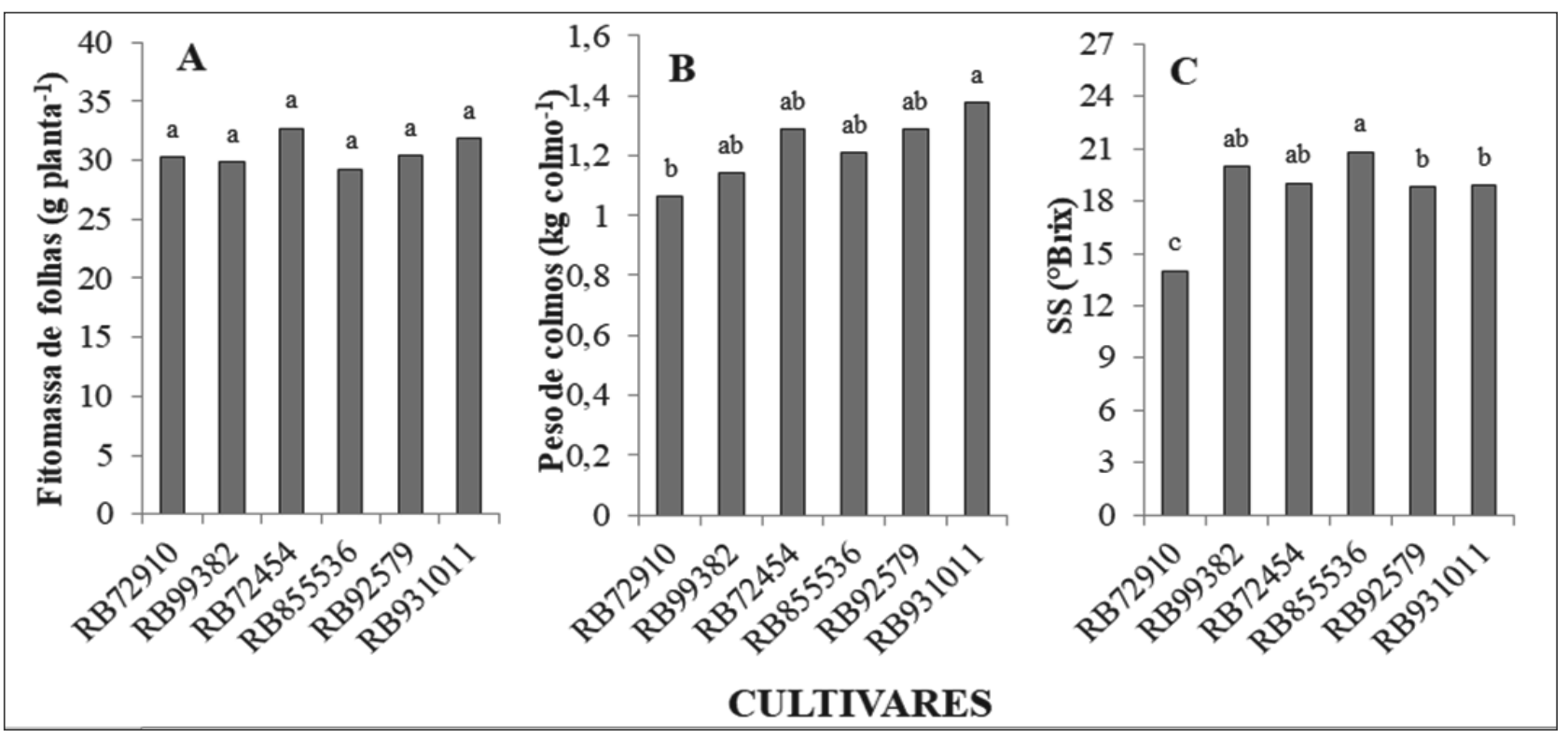


A massa seca de folhas não diferiu entre as cultivares (Figura 3A). A cultivar RB931011 teve maior peso médio de colmo, apresentando um rendimento $23,3 \%$ superior a cultivar RB72910 que teve menor peso médio (Figura 3B). Enquanto a RB855536 teve maior teor de sólidos solúveis, aproximadamente $33 \%$, em relação a cultivar RB72910 que teve o menor (Figura 3C). 0 teor de sólidos solúveis teve correlação positiva com o diâmetro do colmo, e negativa com 0 número de perfilhos aos 240 DAP (Tabela 2).

\section{DISCUSSÃO}

As cultivares RB931011 e RB92579 com maior altura até os 210 DAP sob condições ideais de cultivo, pode indicar que a produção final dessas cultivares se sobressaia às demais. A altura das plantas em canade-açúcar varia bastante entre cultivares, mesmo sob condições semelhantes de cultivo (Almeida et al., 2008; Costa et al., 2011). É importante destacar que a altura da planta é fundamental para o desenvolvimento do dossel, que ocorre, principalmente, em função das características genéticas do material, e pode servir como característica base na triagem de cultivares promissoras (Zhou et al., 2003; Capone et al., 2011).

As correlações da altura da planta em canade-açúcar com outras características morfológicas e produtivas pode ser útil na seleção de cultivares, já que a altura é uma das principais características observadas, e facilmente analisada. Em sorgo, a altura de planta se correlacionou positivamente com o número de folhas e com o número de panículas, atribuindo-se que essa característica contribui no rendimento final da cultura (Nyadanu e Dikera, 2014), o que tem sido observado também em capim-elefante, em que cultivares mais altas produziram maior biomassa de folhas e de colmos (Sollenberger et al., 2014). Portanto, sugere-se que cultivares de cana-de-açúcar com maior altura, tendem a ser mais produtivas. Por estar correlacionada com as características foliares e do colmo, esta característica pode servir como parâmetro de triagem de cultivares nos programas de melhoramento, pois a altura da planta em cana-de-açúcar se correlaciona diretamente com a produtividade (Capone et al., 2011).

0 maior diâmetro do colmo na cultivar RB72454 durante todas as avaliações, sobretudo a partir dos 150 DAP, indica uma característica importante na contribuição da produção final. Oliveira et al. (2004) também observaram em diferentes cultivares de cana-de-açúcar que a cultivar RB72454 teve maior diâmetro, em média 24,7 mm aos 231 DAP. Além das características de cada cultivar, o diâmetro do colmo em cana-de-açúcar também pode sofrer influência do espaçamento utilizado, do número de perfilhos e da área foliar (Almeida et al., 2008; Costa et al., 2011). Entretanto, a diferença entre cultivares é a mais importante devido aos fatores genéticos serem prevalecentes (Souza et al., 2011). Além disso, o diâmetro do colmo teve importantes correlações com o peso de colmos e o teor de sólidos solúveis. Isso sugere, que o diâmetro do colmo pode ser um bom parâmetro no melhoramento da cana-de-açúcar, visto haver boa correlação entre diâmetro e produtividade.

Por outro lado, o diâmetro do colmo teve correlaçãonegativa com onúmero de perfilhos. Resultados semelhantes entre maior diâmetro do colmo e menor perfilhamento foram observados em cana-de-açúcar (Oliveira et al., 2007) e capim-elefante (Sollenberger et al., 2014). 0 baixo perfilhamento em cana-de-açúcar é indicado como fator positivo por promover menor gasto de energia, o que acaba resultando em maior rendimento de colmos, atribuído ao maior acúmulo e conversão de fotoassimilados no crescimento secundário do colmo (Terauchi e Matsuoka, 2000; Oliveira et al., 2004; 2007). 0 baixo perfilhamento na cultivar RB72454 também foi observado por Oliveira et al. (2007). É importante destacar que o perfilhamento produzido na fase de canaplanta, geralmente, é baixo devido ao desenvolvimento do sistema radicular que se encontra em formação, contudo, é também influenciado por fatores endógenos da planta, como o estádio fenológico e as características da cultivar (Almeida et al., 2008).

O número de folhas indica a capacidade fotossintética da planta, além de contribuir na produção de biomassa (Oliveira et al., 2007; Pincelli e Silva, 2012), portanto, deve ser considerada também entre as características correlacionadas. Estes resultados foram semelhantes aos encontrados por Machado et al. (2009), que também observaram maior número de folhas entre 90 e 100 DAP, em duas cultivares de cana-de-açúcar sob condições adequadas de umidade. Dessa forma, pode-se atribuir que o número de folhas reflete diretamente na área foliar, entretanto, depende da cultivar. Por outro lado, o número de folhas teve uma relação fraca com o diâmetro e o peso de colmo, sugerindo que o número de folhas não é um bom parâmetro para selecionar cultivares de cana-de-açúcar 
por não refletir em maior produtividade de colmos.

O comprimento e a largura da folha são características bastante variáveis entre cultivares de cana-de-açúcar (Pincelli e Silva, 2012), além de outras Poaceaes, como capim-elefante (Sollenberger et al., 2014) sendo considerados bons indicadores na seleção de cultivares de cana-de-açúcar (Holanda et al., 2014). Portanto, a largura foliar pode ser um bom parâmetro morfológico para seleção de cultivares de cana-de-açúcar com maior peso de colmo, uma vez que as cultivares de cana-de-açúcar que se sobressaem quanto às dimensões foliares tendem a ser mais produtivas (Pincelli e Silva, 2012).

A área foliar juntamente com a largura foliar, podem ser levadas em consideração na seleção de cultivares quanto a sua capacidade produtiva, sobretudo por apresentarem boa correlação com 0 peso e o diâmetro de colmos, em que este último se correlacionou em todas as cultivares, notadamente na RB931011. De maneira diferente, como a massa seca de folhas não variou entre as cultivares, portanto, não é um bom parâmetro na seleção de cultivares promissoras, como observado por Pincelli e Silva (2012) em diferentes cultivares de cana-de-açúcar sob condições hídricas ideais.

Em cultivares de cana-de-açúcar o aumento na produção de biomassa do colmo tem proporcionado incremento na produtividade, como resultados obtidos por Gava et al. (2011), indicando que a cultivar RB931011 com maior peso de colmos é mais produtiva quando cultivada sob condições adequadas. Além disso, o peso do colmo se correlacionou positivamente com o diâmetro do colmo, a altura da planta, o número de folhas e a área foliar. A correlação entre o diâmetro e o peso do colmo também foi obtida em milho (Beleze et al., 2003), apontando que plantas com maior espessura de colmo tiveram maior produção. Assim, sugere-se que correlações entre características morfológicas e produtivas quando positivas podem ser utilizadas pelos programas de melhoramento como característica diagnóstico, facilitando na seleção de cultivares (Nyadanu e Dikera, 2014).

O teor de sólidos solúveis é um dos atributos qualitativos mais importantes para a indústria canavieira, visto ser um dos componentes que definem o rendimento em açúcar (Costa et al., 2011), sendo considerado satisfatório a partir de $18^{\circ} \mathrm{Bx}$ o que resulta em bom aproveitamento do caldo para a indústria sucroalcooleira (Segato et al., 2006). De acordo com os resultados encontrados nesse estudo, a cultivar RB72910 encontra-se inferior ao padrão. Em diferentes cultivares de cana-de-açúcar em condições de campo, também foi encontrado bom rendimento no teor de sólidos solúveis na cultivar RB855536, cerca de 23,6 ${ }^{\circ} \mathrm{Bx}$ (Capone et al., 2011), entretanto, foi ligeiramente superior ao desse estudo. Cruz et al. (2009) e Costa et al. (2011) avaliando a cultivar RB92579 em condições de campo, observaram teores de 21,9 e $19,5^{\circ} \mathrm{Bx}$, respectivamente, enquanto nesse estudo foi encontrado de $18,8^{\circ} \mathrm{Bx}$. Possivelmente, pode-se atribuir tais valores ao período da avaliação, em que a cana-de-açúcar pode não atingir a maturação até os dez meses após o plantio (Cruz et al., 2009), sugerindo que ao atingirem esse período ou a maturação fisiológica, todas as cultivares mesmo com as diferenças entre elas, estariam acima de $18^{\circ} \mathrm{Bx}$.

A correlação positiva entre o diâmetro do colmo e o teor de sólidos solúveis indica que a espessura do colmo pode influenciar no teor de sacarose, visto que o teor de açúcar está ligado diretamente à capacidade de reserva que o colmo pode armazenar. Em cana-deaçúcar, o acúmulo de sacarose é adequado nas células parenquimatosas dos colmos quando as plantas não estão sob limitação hídrica (Dias et al., 2012). Por outro lado, a redução no teor de sólidos solúveis em relação ao aumento do número de perfilhos pode ser atribuída ao maior gasto de fotoassimilados, necessários para 0 desenvolvimento dos perfilhos (Oliveira et al., 2004).

0 maior diâmetro do colmo e menor perfilhamento na cultivar RB72454, a maior altura de planta e largura da folha na RB92579, e a maior altura de planta na RB931011 se mostraram determinantes na contribuição para maior produção de peso de colmos em condições adequadas de umidade.

O perfilhamento tem correlação negativa com 0 diâmetro do colmo e o teor de sólidos solúveis, enquanto que, o diâmetro do colmo tem correlação positiva com o teor de sólidos solúveis e o peso de colmos.

A área e a largura foliar se mostraram como boas características que podem ser utilizadas na seleção de cultivares promissoras de cana-de-açúcar, por terem fortes correlações com a produção de colmos.

As correlações obtidas entre características morfológicase produtivas podem serúteisaosmelhoristas no direcionamento da escolha de cultivares superiores, visto que a partir de características morfológicas simples 
é possível selecionar cultivares promissoras devido às correlações com a produção, sem a necessidade de acompanhar todo o ciclo da planta.

\section{AGRADECIMENTOS}

Os autores agradecem ao Banco do Nordeste e a Coordenação de Aperfeiçoamento de Pessoal de Nível Superior pelo apoio financeiro.

\section{REFERÊNCIAS BIBLIOGRÁFICAS}

Almeida, A. C. S.; Souza, J. L.; Teodoro, I.; Barbosa, G. V. S; Moura Filho, G.; Ferreira Júnior, R. A. Desenvolvimento vegetativo e produção de variedades de cana-de-açúcar em relação à disponibilidade hídrica e unidades térmicas. Ciência e Agrotecnologia, 2008, $32,5,1441-1448$.

Beleze, J. R. F., Zeoula, L. M., Cecato, U., Dian, P. H. M., Martins, E. N., Falcão, A. D. S. Avaliação de cinco híbridos de milho (Zea mays, L.) em diferentes estádios de maturação. 1. Produtividade, características morfológicas e correlações. Revista Brasileira de Zootecnia, 2003, 32, 3, 529-537.

Capone, A., Lui, J. J., Silva, T. R., Dias, M. A. R., Melo, A. V. Avaliação do comportamento de quinze cultivares de cana-de-açucar na Região Sul do Tocantins. Journal of Biotechnology and Biodiversity, 2011, 2, 3, 72-80.

Carlin, S. D.; Santos, D. M. M. Indicadores fisiológicos da interação entre déficit hídrico e acidez do solo em cana-de-açúcar. Pesquisa Agropecuária Brasileira, 2009, 44, 9, 1106-1113.

Casler, M. D., Vogel, K. P., Taliaferro, C. M., Wynia, R. L. Latitudinal adaptation of switchgrass populations. Crop Science, 2004, 44, 1, 293-303.

Conab (Companhia Nacional de Abastecimento) 2017. Disponível: <http://www.conab.gov.br>. Acessado em: março de 2017.

Costa, C. T. S.; Ferreira, V. M.; Endres, L.; Ferreira, D. T. R. G.; Gonçalves, E. R. Crescimento e produtividade de quatro variedades de cana-de açúcar no quarto ciclo de cultivo. Revista Caatinga, 2011, 24, 3, 56-63.
Cruz, S. J. S.; Oliveira, S. S. C., Cruz, S. C. S., Machado, C. G.; Pereira, R. G. Efeito da adubação fosfatada sobre 0 acúmulo de biomassa e teor de brix de duas variedades de cana-de-açúcar. Revista Caatinga, 2009, 22, 2, 110-116.

Dias, C. M. O.; Corsato, C. E.; Santos, V. M.; Santos, A. F. S. Indicadores fitotécnicos, de produção e agroindustriais em cana de açúcar cultivada sob dois regimes hídricos. Revista Caatinga, 2012, 25, 3, 58-65.

Gava, G. J. C., Silva, M. A., Silva, R. C., Jeronimo, E. M., Cruz, J. C. S., Kölln, O. T. Produtividade de três cultivares de cana-de-açúcar sob manejos de sequeiro e irrigado por gotejamento. Revista Brasileira de Engenharia Agrícola e Ambiental, 2011, 15, 3, 250-255.

Hermann, E. R.; Câmara, G. M. S. Um método simples para estimar a área foliar de cana-de-açúcar. Revista STAB - Açúcar, Álcool e Subprodutos, 1999, 17, 5, 3234.

Holanda, L. A., Santos, C. M., Sampaio Neto, G. D., Sousa, A. P., Silva, M. A. Variáveis morfológicas da cana-de-açúcar em função do regime hídrico durante 0 desenvolvimento inicial. Irriga, 2014, 19, 573-584.

Machado, R.S.; Ribeiro, R.V.; Marchiori, P.E.R.; Machado, D.F.S.P.; Machado, E.C.; Landell, M.G. de A. Respostas biométricas e fisiológicas ao déficit hídrico em cana-de-açúcar em diferentes fases fenológicas. Pesquisa Agropecuária Brasileira, 2009, 44, 15751582.

Medeiros, D. B.; Silva, E. C.; Nogueira, R. J. M. C.; Teixeira, M. M.; Buckeridge, M. S. Physiological limitations in two sugarcane varieties under water suppression and after recovering. Theoretical and Experimental Plant Physiology, 2013, 25, 3, 213-222.

Nyadanu, D.; Dikera, E. Exploring variation, relationships and heritability of traits among selected accessions of sorghum (Sorghum bicolor L. Moench) in the upper east region of Ghana. Journal of Plant Breeding and Genetics, 2014, 2, 3, 101-107.

Oliveira, R. A.; Daros, E.; Zambon, J. L. C.; Weber, H.; Ido, O. T.; Zuffelato-Ribas, K. C.; Koehler, H. S.; Silva, D. K. T. Crescimento e desenvolvimento de três cultivares 
de cana-de-açúcar, em cana planta, no Estado do Paraná. Scientia Agrária, 2004, 5, 1-2, 87-94.

Oliveira, R. A.; Daros, E.; Zambon, J. L. C.; Weber, H.; Ido, O. T.; Bespalhok-Filho, J. C.; Zuffelato-Ribas, K. C.; Silva, D. K. T. Área foliar em três cultivares de cana-deaçúcar e sua correlação com a produção de biomassa. Pesquisa Agropecuária Tropical, 2007, 37, 2, 71-76.

Pincelli, R. P; Silva, M. A. Alterações morfológicas foliares em cultivares de cana-de-açúcar em resposta à deficiência hídrica. Bioscience Journal, 2012, 28, 4.

Sales, C. R. G.; Ribeiro, R. V.; Machado, D. F. S. P.; Machado, R. S.; Dovis, V. L.; Lagôa, A. M. M. A. Trocas gasosas e balanço de carboidratos em plantas de cana-de-açúcar sob condições de estresses radiculares. Bragantia, 2012, 71, 319-327.

Santos, J. R.; Oliveira Junior, L. F. G.; Sousa, J. P. S.; Silva Junior, C. D.; Sarmento, C. R. Desempenho de genótipos promissores de cana-de-açúcar utilizando ferramentas fisiológicas e biométricas. Bioscience Journal, 2014, 30, 1, 380-389.

Segato, S. V., Pinto, A. D. S., Jendiroba, E., Nóbrega, J. D. Atualização em produção de cana-de-açúcar. Piracicaba: Livroceres, 2006, 19-36.

Shigaki, F.; Freitas, N.; Berto A.; Ceddia, M. B.; Zonta, E.; LIMA, E. Influência do estresse hídrico nos parâmetros de crescimento, acúmulo de $\mathrm{N}$ e produtividade de diferentes variedades de cana-de-açúcar em Miracema - RJ. Revista Universidade Rural: Série Ciências da Vida, 2004, 24, 1, 63-71.

Silva, M. A.; Jifon, J. L.; Silva, J. A. G.; Sharma, V. Use of physiological parameters as fast tools to screen for drought tolerance in sugarcane. Brazilian Journal of Plant Physiology, 2007, 19, 3, 193-201.
Silva, M. A.; Jifon, J. L.; Silva, J. A. G.; Santos, C.M.; Sharma, V. Relationships between physiological traits and productivity of sugarcane in response to water deficit. Journal of Agricultural Science, 2012, 151, 1, 104-118.

Sollenberger, L. E., Woodard, K. R., Vendramini, J. M., Erickson, J. E., Langeland, K. A., Mullenix, M. K., NA, C. Castillo, M. S., Gallo, M., Chase, C. D., López, Y. Invasive populations of elephantgrass differ in morphological and growth characteristics from clones selected for biomass production. BioEnergy Research, 2014, 7, 4, 1382-1391.

Souza, A. E. R.; Oliveira, F. J.; Anunciação Filho, C. J.; Melo Filho, P. A.; Melo, J. L. O. T.; Tabosa, J. N. Seleção de famílias RB visando à alta produtividade $\mathrm{e}$ precocidade na maturação em cana-de-açúcar. Revista Bragantia, 2011, 70, 4, 788-795.

Terauchi, T.; Matsuoka, M. Ideal characteristics for the early growth of sugarcane. Japanese Journal of Crop Science, 2000, 69, 3, 286-292.

Van Dillewijn, C. Botany of sugarcane. Waltham: Chronica Botanica, 1952. $371 \mathrm{p}$.

Vieira, G. H. S.; Mantovani, E. C.; Sediyama, G. C.; Delazari, F. T. Indicadores morfo-fisiológicos do estresse hídrico para a cultura da cana-de-açúcar em função de lâminas de irrigação. Bioscience Journal, 2014, 30, 1, 65-75.

Vitti, G. C.; Luz, P.H.C.; Altran, W. S. Nutrição e adubação. In: Santos F.; Borém, A. (eds) Cana-deaçúcar: do plantio à colheita. UFV, 2013.

Zhou, M.; Singels, A.; Savage, M. J. Physiological parameters for modelling differences in canopy development between sugarcane cultivars. South African Sugarcane Research Institute: Embracing biotechnology for crop improvement research, 2003, $77,610-621$. 